\title{
Mammographic screening for breast cancer: Are the chickens coming home to roost?
}

A paradigm challenging observational study on screening mammography was published in the New England Journal of Medicine (NEJM) on Thanksgiving Day. ${ }^{[1]}$ Its main conclusions were an indictment of the huge population-based mammographic screening effort undertaken in Western nations in the last three decades. The authors concluded that screening mammography has substantially increased the number of early stage breast cancer cases, only marginally reduced advanced stage presentation, resulted in substantial overdiagnosis, and has had little or no effect on population breast cancer mortality. The authors of this study are not lone rangers. There have been several voices and datasets urging restraint in the unbridled enthusiasm and advocacy to adopt this procedure as the principal method for global breast cancer control, ${ }^{[2-6]}$ although there continue to be many uncritical enthusiasts. ${ }^{[7]}$ It is a telling commentary on changing times that the word 'harms' is beginning to be uttered in the same breath as breast cancer screening. ${ }^{[6]}$ The NEJM study is especially relevant to the Indian and developing country context and has many lessons that we will, hopefully, not ignore. ${ }^{[8]}$ Although the ramifications of this study may upset long held beliefs, especially in those who uncritically follow 'guidelines', that is unlikely to be the case for incisive clinicians, researchers, and members of the public who filter all information through a 'lens'. The 'lens' for any health intervention in cancer ought to have its impact on incidence, cause-specific and all-cause mortality, and the length and quality of survival after diagnosis. Screening mammography is no exception.

Randomized trials with over 600,000 healthy women have contributed to our knowledge about the benefits of screening mammography or lack thereof. The data from these trials and well-monitored population-based screening programs suggest that mammography results in overdiagnosis to the extent of about $25-30 \%{ }^{[1,9,10]}$ The practical interpretation of this statistics is that the cancer in 1 out of 3 to 4 women diagnosed though screening mammography would either never have surfaced during their remaining lifetimes or only after a couple of decades of the mammographic label. There is further 'molecular' evidence, for those who care for nothing less, that breast cancer screening preferentially detects ultra-low risk tumors - a more refined vocabulary for overdiagnosis. ${ }^{[11]}$ It must be admitted that the body of

\begin{tabular}{|l|l|}
\hline \multicolumn{2}{|c|}{ Access this article online } \\
\hline Quick Response Code: & Website: \\
\hline & www.sajc.org \\
\cline { 2 - 3 } & \\
\hline
\end{tabular}

evidence on mammographic screening is somewhat counterintuitive - it challenges the long-held dogma that earlier detection of tumors (when they are smaller) should save lives since survival is better with decreasing tumor size. Population-based randomized studies, comparing mammographic screening to either no screening or physical examination, have indeed proven the downstaging effect of this procedure. However, the effect on mortality is far more complex and uncertain - there is a singular lack of unequivocal evidence of beneficial effect in women younger than 50 years. ${ }^{[12]}$ In women above 50 years there are several nuances, the chief one being that although there is a $23 \%$ reduction in breast cancer mortality, there is no beneficial effect on all-cause mortality in randomized trials. $^{[12]}$ The likely reason for such an outcome is the possible biased misclassification of cause of deaths in the randomized arms favoring the screened group. ${ }^{[12]}$ There is, thus, little surprise that the observational study from US showed little or no effect on breast cancer mortality.

On a more human and less statistical note, the women, thus, overdiagnosed ( 1 in 3 to 4 ) experience both the travails and triumphs of their label - usually more of the former, but also some of the latter. They face the near certainty of a surgeon's knife and the overwhelming odds of being at the receiving end of other 'multidisciplinary' handymen - radiotherapists and chemotherapists being the most prominent. The psychological implications of the label are complex - chiefly the profound trauma of this diagnosis, but also the sense of conquest over a 'dreaded' foe.

Overall, we might consider ourselves lucky that many more women in urban India have not acquired this label, which would have been a near certainty in the presence of a population mammographic program. Now, with accumulating analyses and new evidence, there is simply no case for introduction of this screening modality in developing countries, especially in view of their young 'bottom heavy' population pyramids. On a more general note the increased precision of all new technologies ought to be filtered through the 'lens'. In this context, breast MRI, thermoscans, positron emission mammography and others immediately come to the mind. Only then will we not tread the same three decades that some Western countries have with screening mammography. Finally, it is good to remind ourselves that the real aim of breast cancer control is not to detect 'early cancers' but to reduce the incidence of this disease, which is already the case in large swathes of our rural population.

\footnotetext{
Rajendra A. Badwe, Sudeep Gupta Department of Surgical Oncology, Tata Memorial Centre, Mumbai, India Correspondence to: Dr. Rajendra A Badwe E-mail: badwera@tmc.gov.in
} 


\section{References}

1. Bleyer A, Welch HG. Effect of three decades of screening mammography on breast-cancer incidence. N Engl J Med 2012;367: 1998-2005.

2. U.S. Preventive Services Task Force. Screening for Breast Cancer: U.S. Preventive Services Task Force Recommendation Statement. Ann Intern Med 2009; 151:716-26.

3. Woloshin S, Schwartz LM, Black WC, Kramer BS. Cancer screening campaigns-getting past uninformative persuasion. N Engl J Med 2012;367:1677-9.

4. Gøtzsche PC. Relation between breast cancer mortality and screening effectiveness: Systematic review of the mammography trials. Dan Med Bul 2011;58:A4246.

5. Autier P, Koechlin A, Smans M, Vatten L, Boniol M. Mammography screening and breast cancer mortality in Sweden. J Natl Cancer Inst 2012; 104:1080-93.

6. Independent UK Panel on Breast Cancer Screening. The benefits and harms of breast cancer screening: An independent review. Lancet 2012;380: 1778-86.

7. Bock K, Borisch B, Cawson J, Damtjernhaug B, de Wolf C, Dean P, et al. Effect of population-based screening on breast cancer mortality. Lancet 2011;378:1775-6.
8. Badwe RA, Gupta S. Breast cancer: An Indian perspective. Natl Med J India 2011;24:193-7.

9. Kalager M, Adami HO, Bretthauer M, Tamimi RM. Overdiagnosis of invasive breast cancer due to mammography screening: Results from the Norwegian screening program. Ann Intern Med 2012; 156:491-9.

10. Elmore JG, Fletcher SW. Overdiagnosis in breast cancer screening: Time to tackle an underappreciated harm. Ann Intern Med 2012; 156:536-7.

11. Esserman LJ, Shieh Y, Rutgers EJ, Knauer M, Retèl VP, Mook S, et al. Impact of mammographic screening on the detection of good and poor prognosis breast cancers. Breast Cancer Res Treat 2011;130:725-34.

12. Gøtzsche PC, Nielsen M. Screening for breast cancer with mammography. Cochrane Database of Systematic Reviews 2011:CD001877.

How to cite this article: Badwe RA, Gupta S. Mammographic screening for breast cancer: Are the chickens coming home to roost?. South Asian J Cancer 2013;2:1-2.

Source of Support: Nil. Conflict of Interest: None declared. 